\title{
Go with the Flow: The Importance of the Assessment of Collateral Ventilation in Endobronchial Valve Treatment
}

\author{
Dirk-Jan Slebos ${ }^{\mathrm{a}}$ Pallav L. Shah ${ }^{\mathrm{b}, \mathrm{c}}$ \\ ${ }^{a}$ Department of Pulmonary Diseases, University Medical Center Groningen, University of Groningen, Groningen, \\ The Netherlands; ${ }^{\mathrm{b}} \mathrm{NIHR}$ Respiratory Biomedical Research Unit at the Royal Brompton and Harefield NHS Foundation \\ Trust, Imperial College, and ${ }^{\mathrm{C} C h e l s e a}$ and Westminster Hospital, London, UK
}

Bronchoscopic lung volume reduction using one-way endobronchial valves (EBV) for patients with severe emphysema is evolving into a guideline therapy for this patient group [1]. The elegance of this invasive bronchoscopic intervention consists in the fact that responders to this treatment can nowadays be very accurately selected: a great example of precision medicine. From the VENT study, we have already learned the importance of both a full lobar treatment with and technically successful placement of EBV as well as fissure completeness being a key to EBV treatment success [2]. The VENT trial showed that we needed a tool which could prospectively evaluate the suitability of the individual patient for EBV treatment. To do this, both a very vigorous analysis of the interlobar fissure on a thin-slice computed tomography (CT) of the thorax [3] or using an effective functional measurement of the interlobar collateral flow [4] are possible options.

The multicenter European Chartis trial validated the use of the Chartis system, a bronchoscopic catheter-based system that can accurately measure, in real-time, the interlobar collateral flow between the treatment target lobe and the adjacent lobe [5]. This trial also showed similar predictive values for both CT fissure analysis or the Chartis system [5]. So, to be able to identify our responders, do we need CT or Chartis, or maybe both? A direction towards an answer to this question has recently been pro-

\begin{tabular}{ll}
\hline KARGER & $\begin{array}{l}\text { ( } 2016 \text { The Author(s) } \\
\text { Published by S. Karger AG, Basel } \\
\text { Openger }\end{array}$ \\
E-Mail karger@karger.com & $0025-7931 / 16 / 0914-0269 \$ 39.50 / 0$ \\
www.karger.com/res & This article is licensed under the Creative Commons Attribution- \\
& NonCommercial-NoDerivatives 4.0 International License (CC BY- \\
& NC-ND) (http://www.karger.com/Services/OpenAccessLicense). \\
& Usage and distribution for commercial purposes as well as any dis- \\
& tribution of modified material requires written permission.
\end{tabular}

vided. At first, the BeLieVeR-HIFi study, a sham-controlled, randomized trial of EBV treatment, where visual assessment of fissure integrity by CT scan was used to select patients, showed a significant benefit in favor of EBV treatment over control [6]. However, post hoc analysis revealed that if the Chartis system (which was performed in this trail) had been used to select the patients, the outcome would have been significantly better. Second, Schuhmann et al. [7] reported a response rate of $65 \%$ to EBV treatment if the fissure was $>90 \%$ on CT. Nevertheless, this means that there is a significant proportion of patients without response. Finally, Klooster et al. [1] showed the real value of both the EBV treatment and optimal patient selection for this treatment. In the STELVIO trial, a randomized controlled trial to compare EBV treatment with standard medical care, CT scan was used to preselect potential candidates, but the Chartis assessment determined whether the patients were included in the trial. In the STELVIO trial, the EBV group improved very significantly in $\mathrm{FEV}_{1}$ $(+22.7 \%)$ and 6MWD $(106 \mathrm{~m})$ compared to the control group. Based on this data, the Chartis system should be recommended to optimize treatment outcome, and thus avoiding unnecessary and costly treatment.

The article by Herzog et al. [8] published in a recent issue of Respiration is a further step in improving the use of the Chartis system. The paper elegantly describes the

Dr. Dirk-Jan Slebos, MD, PhD

Department of Pulmonary Diseases, AA11, University Medical Center Groningen PO Box 30001

NL-9700 RB Groningen (The Netherlands)

E-Mail d.j.slebos@umcg.nl 
collateral flow pattern 'phenotypes' that can be encountered during the assessment, thereby serving as a guidance to everyone using this technique. The correct interpretation of the Chartis findings is the key to success in EBV treatment. Performing the Chartis procedure in experienced hands is feasible and on average takes $10 \mathrm{~min}$ of procedure time, with less than $5 \%$ of indeterminable results. The procedure is easier and more reproducible in ventilated patients under general anesthesia, but can be more challenging with spontaneously breathing patients under minimal conscious sedation. Herzog et al. [8] observed four phenotypes: (1) collateral ventilation positive (persistent expiratory flow and no increase in the resistance index over $5 \mathrm{~min}$ ), (2) collateral ventilation negative (steady decline in expiratory flow with a corresponding increase in the resistance index), (3) low flow pattern (rapid decline in expiratory flow and increase in the resistance index within $30 \mathrm{~s}$ of the onset of measurement and with less than $100 \mathrm{ml} / \mathrm{s}$ expired in total), and (4) low plateau pattern (decrease in expiratory flow which then plateaus and absence of a significant increase in the resistance index over $5 \mathrm{~min}$ ). The low flow phenotype is predominantly observed in the lower lobes and may be secondary to dynamic airway collapse; hence, further evaluation of the ipsilateral lobe may be of value. Other pitfalls to consider are correct occlusion with the balloon and occlusion of the catheter with mucus.

Greater clinician understanding of and familiarity with the Chartis procedure as well as correct interpretation of the findings are invaluable tools in patient selection that will further optimize EBV treatment to a highly personalized level.

\section{References}

-1 Klooster K, Ten Hacken NHT, Hartman JE, Kerstjens HM, van Rikxoort EM, Slebos DJ: Endobronchial valves for emphysema without interlobar collateral ventilation. N Engl J Med 2015;373:2325-2335.

$\checkmark 2$ Sciurba FC, Ernst A, Herth FJ, et al: A randomized study of endobronchial valves for advanced emphysema. N Engl J Med 2010; 363:1233-1244.

-3 Koenigkam-Santos M, Puderbach M, Gompelmann $\mathrm{D}$, et al: Incomplete fissures in severe emphysematous patients evaluated with MDCT: incidence and interobserver agreement among radiologists and pneumologists. Eur J Radiol 2012;81:4161-4166.
4 Aljuri N, Freitag L: Validation and pilot clinical study of a new bronchoscopic method to measure collateral ventilation before endobronchial lung volume reduction. J Appl Physiol 2009;106:774-783.

5 Herth FJ, Eberhardt R, Gompelmann D, et al: Radiological and clinical outcomes of using Chartis to plan endobronchial valve treatment. Eur Respir J 2013;41:302-308.

$\checkmark 6$ Davey C, Zoumot Z, Jordan S, et al: Bronchoscopic lung volume reduction with endobronchial valves for patients with heterogeneous emphysema and intact interlobar fissures (the BeLieVeR-HIFi study): a randomised controlled trial. Lancet 2015;386: 1066-1073.
7 Schuhmann M, Raffy P, Yin Y, et al: Computed tomography predictors of response to endobronchial valve lung reduction treatment. Comparison with Chartis. Am J Respir Crit Care Med 2015;191:767-774.

8 Herzog D, Thomsen C, Poellinger A, et al: Outcomes of endobronchial valve treatment based on precise criteria of an endobronchial catheter for detection of collateral ventilation under spontaneous breathing. Respiration 2016;91:69-78. 